\title{
DELIBERASI UNTUK DEMOKRASI PASCA PANDEMI DI INDONESIA
}

Sejak pandemi Covid-19 melanda, kebijakan pembatasan sosial diberlakukan, akibatnya banyak sektor ekonomi yang tidak berkembang bahkan bangkrut. Sehingga, indeks gini atau ketimpangan ekonomi di Indonesia meningkat pada 2020. Data lain mengungkap angka kemiskinan Indonesia meningkat pada 2020 menjadi 10,19\% dibandingkan daripada tahun-tahun sebelumnya yang menunjukan angka di bawah dua digit. Selain itu, beberapa polemik juga muncul dalam penyaluran bantuan sosial saat pandemi seperti ketidaktepatan pendataan, sasaran bantuan, bahkan korupsi. Meski demikian, gerakan-gerakan aktivisme sosial untuk saling membantu rakyat dan dari rakyat juga bermunculan saat pandemi. Jalur daring dan aplikasi perangkat lunak adalah beberapa piranti yang digunakan untuk menjaring bantuan untuk sesama. Aktivisme sosial dapat dikolaborasikan untuk meningkatkan akuntabilitas bantuan sosial pemerintah dan pertumbuhan ekonomi pasca pandemi. Sebab, aktivisme sosial yang bermula dari gerakan untuk membantu diri (self-help) memiliki kecenderungan untuk lebih tangguh dalam menjamin akuntabilitas, mengurangi manipulasi politik, menghimpun dan menyalurkan bantuan daripada lembaga bentukan pemerintah terutama pada saat pandemi di Negara berkembang (Haberer et al., 2021). Aktivisme sosial dapat menjadi kolaborator dalam demokrasi deliberatif saat pandemi. Bahkan, sebuah meta-analisis dari studi-studi eksperimental di negara berpendapatan rendah, menengah, dan tinggi menemukan bahwa pengawasan dari gerakan masyarakat dapat mengurangi tindakan korupsi (Mugellini et al., 2021).

\section{Demokrasi Deliberatif}

Demokrasi deliberatif adalah sebuah konsep di mana masyarakat dalam posisi yang setara hadir bersama secara logis dalam sebuah ruang publik untuk berkontribusi dan mengambil keputusan yang mempengaruhi hidup mereka dan orang lain dalam kelompoknya (Bächtiger et al., 2018). Dalam cakupan jumlah warga yang besar, demokrasi deliberatif dapat diterapkan dengan melibatkan aktor kunci yang berasal dari masyarakat, aktivis sosial, dan bukan perwakilan yang secara formal ditunjuk oleh pemerintah. Sebab, actor kunci yang berasal dari masyarakat tanpa ikatan formal dapat menjadi intelektual organik, atau seperti konsep Antonio Gramsci, menjadi penyalur pendapat yang memahami, dipercaya dan menyelesaikan masalah masyarakat (Cole, 2019).

Demokrasi deliberatif mengakselerasi pertumbuhan ekonomi inklusif, kualitas pengambilan keputusan, akuntabilitas, ikatan sosial, kepercayaan, dan pengetahuan warga (Aparicio et al., 2021). Deliberasi krusial bagi penyusunan dan implementasi kebijakan publik yang strategis. Masyarakat cenderung lebih puas dengan hasil konsensus dan kontribusi mereka dalam menyelesaikan suatu isu meski tidak mencerminkan pendapat pribadi mereka. Salah satu wujud demokrasi deliberatif saat ini adalah penyaluran pendapat dan bantuan pada ruang publik yang dapat kita sebut aktivisme media sosial.

\section{Tantangan Demokrasi Deliberatif bagi Indonesia}

Demokrasi di Indonesia tidak hanya dipahami sebatas politik elektoral dan keterwakilan, namun juga secara budaya mengacu pada musyawarah mufakat. Artinya, ada jaminan bagi warga untuk berpartisipasi lebih luas secara sosial dan ekonomi. Meski 
demikian, indeks demokrasi Indonesia sebagaimana dievaluasi oleh Economist Intelligence Unit (EIU) pada 2018 masih berada dalam kategori tidak sempurna. Sebagaimana laporan EIU, terbatasnya kebebasan individu dalam berpendapat dan budaya berpolitik di Indonesia masih kurang matang. Terlihat dengan nilai indeks demokrasi yang menurun pada 2020. Maka, terdapat beberapa hal yang perlu diperbaiki dari deliberasi di Indonesia.

Pertama, ruang publik untuk berekspresi termasuk di dalamnya akses kepada media sosial seluasnya tak perlu dibatasi. Sebab, media sosial merupakan wadah besar untuk aktivisme sosial saat pandemi.

Kedua, pematangan budaya berpolitik. Data Mafindo pada 2019 menyimpulkan frekuensi berita palsu dan misinformasi meningkat $61 \%$ dibandingkan tahun sebelumnya dan secara dominan tersebar melalui facebook (Putra Salatananda Williem, 2020). Dengan akses informasi makin luas, kian banyak informasi yang tidak tepat dan tidak diperlukan masyarakat dalam mengambil keputusan. Terlebih dengan kemampuan literasi warga yang berbeda-beda. Wijaya, (2019) mewawancara lima media besar di Indonesia dan melakukan survey pada 287 pembaca, ia mengungkap bahwa manipulasi informasi adalah masalah terbesar yang dihadapi konsumen media masa yang memiliki jalurnya di media sosial. Konsekuensi lebih jauh dapat dibayangkan berupa besarnya kemungkinan provokasi dari berita palsu. Sementara itu, pemerintah juga memiliki tangung jawab menjaga ketertiban dan keamanan warga.

\section{Warga Deliberatif}

Dalam pelaksanaan deliberasi, Esterling et al., (2015) pada studi terhadap 2000 warga partisipan kebijakan kesehatan di Amerika mempersyaratkan kemampuan warga untuk mengartikulasikan alasan pendapatnya berbasis bukti dan juga memberi solusi disamping ketidaksepahaman yang pasti terjadi. Sebab, demokrasi deliberatif sangat menantang saat forum berisi partisipan yang memiliki nilai, kepercayaan, dan kepentingan yang berbeda. Diskusi yang logis dan konstruktif hendaknya lebih diunggulkan. Studi Esterling et al, (2015) juga membawa pada prasyarat pertama demokrasi deliberatif, yakni konsensus bersama yang menjamin proses diskursus berjalan tanpa tekanan atau diskriminasi.

Prasyarat kedua agar demokrasi deliberatif berjalan efektif yakni warga perlu memiliki kemampuan untuk mengakses dan mencerna informasi yang tepat. Ini memerlukan daya kritis dan literasi media yang juga dibiasakan dalam sistem pendidikan. Sebuah studi menyatakan minat baca berkontribusi pada daya ingat dan kemampuan kognitif warga dalam pengambilan keputusan (Sol et al., 2021). Mendatang, perlu tinjauan berbasis bukti tentang protokol kebijakan arus informasi terutama saat darurat tanpa membatasi akses warga. Program literasi digital yang saat ini juga digalakan oleh Kementerian Komunikasi dan Informatika juga perlu dilanjutkan. Tidak hanya itu saja, pemerintah perlu meningkatkan kolaborasi dengan para aktivis sosial dalam program literasi digital dan penyusunan jalur pengawasan oleh masyarakat.

Prasyarat-prasyarat di atas amat mungkin dipenuhi masyarakat Indonesia terutama generasi muda. Survei IDN Research Institute, (2019) yang melibatkan 1400 responden milenial di 12 kota besar di Indonesia menunjukan bahwa $89 \%$ responden merasa optimis dengan perbedaan identitas di Indonesia. Meski demikian, menurut mereka, performa ekonomi, politik dan hukum masih perlu diperbaiki. Riset tersebut mengungkap pula, generasi milenial lebih aktif pada media sosial dan menjadi agen melawan misinformasi dan berita palsu.

Aktivisme sosial merupakan gerakan yang dekat secara sosial dan lebih dipercaya masyarakat. Sebab, dalam beberapa praktik bahkan dapat meningkatkan akuntabilitas dan pertumbuhan ekonomi yang inklusif. Semoga pada masa mendatang, aktivisme sosial 
dipertimbangkan menjadi salah satu potensi yang dapat meningkatkan kinerja pemerintah (Pratiwi).

\section{Referensi :}

Aparicio, S., Audretsch, D., \& Urbano, D. (2021). Does Entrepreneurship Matter for Inclusive Growth? The Role of Social Progress Orientation. Entrepreneurship Research Journal, 11(4). https:// doi.org/10.1515/erj-2019-0308

Bächtiger, A., Dryzek, J. S., Mansbridge, J., \& Warren, M. (2018). The Oxford handbook of deliberative democracy. Oxford University Press.

Cole, J. (2019). Experts and exiles: Organic intellectuals, education, and the "indian problem" in postwar ontario, canada. Paedagogica Historica, 55(2), 207-222. https://doi.org/10.1080/00309230.2018.1482499

Esterling, K. M., Fung, A., \& Lee, T. (2015). How Much Disagreement is Good for Democratic Deliberation? Political Communication, 32(4). https://doi.org/10.1080/10584609.2014.969466

Haberer, J. E., van der Straten, A., Safren, S. A., Johnson, M. O., Amico, K. R., del Rio, C., Andrasik, M., Wilson, I. B., \& Simoni, J. M. (2021). Individual health behaviours to combat the COVID-19 pandemic: lessons from HIV socio-behavioural science. Journal of the International AIDS Society, 24(8). https:/ / doi.org/10.1002/jia2.25771

IDN Research Institute. (2019). Indonesia Millennial Report 2019.

Mugellini, G., Della Bella, S., Colagrossi, M., Isenring, G. L., \& Killias, M. (2021). Public sector reforms and their impact on the level of corruption: A systematic review. Campbell Systematic Reviews, 17(2). https:/ / doi.org/10.1002/cl2.1173

Putra Salatananda Williem, S. (2020). Peran Masyarakat Anti Fitnah Indonesia (MAFINDO) sebagai Jembatan Penghubung Reciprocal Journalism dalam Area Fact Checking.

Sol, K., Sharifian, N., Manly, J. J., Brickman, A. M., \& Zahodne, L. B. (2021). Associations between loneliness, reading ability and episodic memory in non-hispanic black and white older adults. Archives of Clinical Neuropsychology, 36(6), 1003-1011. https://doi.org/10.1093/arclin/acab001

Wijaya, B. S. (2019). Dancing with the impropriety of media: How Indonesian consumers think and behave towards the unethical and illogical online news. Jurnal Komunikasi: Malaysian Journal of Communication, 35(1). 